\title{
$2{ }^{\circ}$ Encontro Nacional de Química Terapêutica 2010
}

A Universidade de Coimbra acolheu o $2^{\circ}$ Encontro Nacional de Química Terapêutica, que se realizou entre 28 e 30 de Novembro de 2010, sob os auspícios da SPQ e com o patrocínio da European Federation for Medicinal Chemistry, EFMC.

De acordo com o Grupo de Química Terapêutica, GQT, foi mantida a periodicidade bienal, tendo o Encontro atraído excelentes contribuições científicas, em que foi dada ênfase aos avanços mais recentes na interface da Química, Biologia, Bioquímica Computacional e Medicina Experimental, e sua importância no estado da arte da descoberta e desenvolvimento de fármacos.

O Encontro reuniu 173 participantes, tendo decorrido no novo Pólo das Ciências da Saúde da Universidade de Coimbra, no domingo 28 de Novembro, e nos dias seguintes no Hotel Vila Galé Coimbra.

A Comissão Organizadora, presidida por M. Luisa Sá e Melo, Presidente do Grupo de Química Terapêutica de 2007 a 2010, elegeu um conjunto de temáticas que incluíram a descoberta de novos fármacos na área do cancro e de novos alvos para fármacos com utilidade no sistema nervoso, bem como os desenvolvimentos mais recentes no tratamento e prevenção

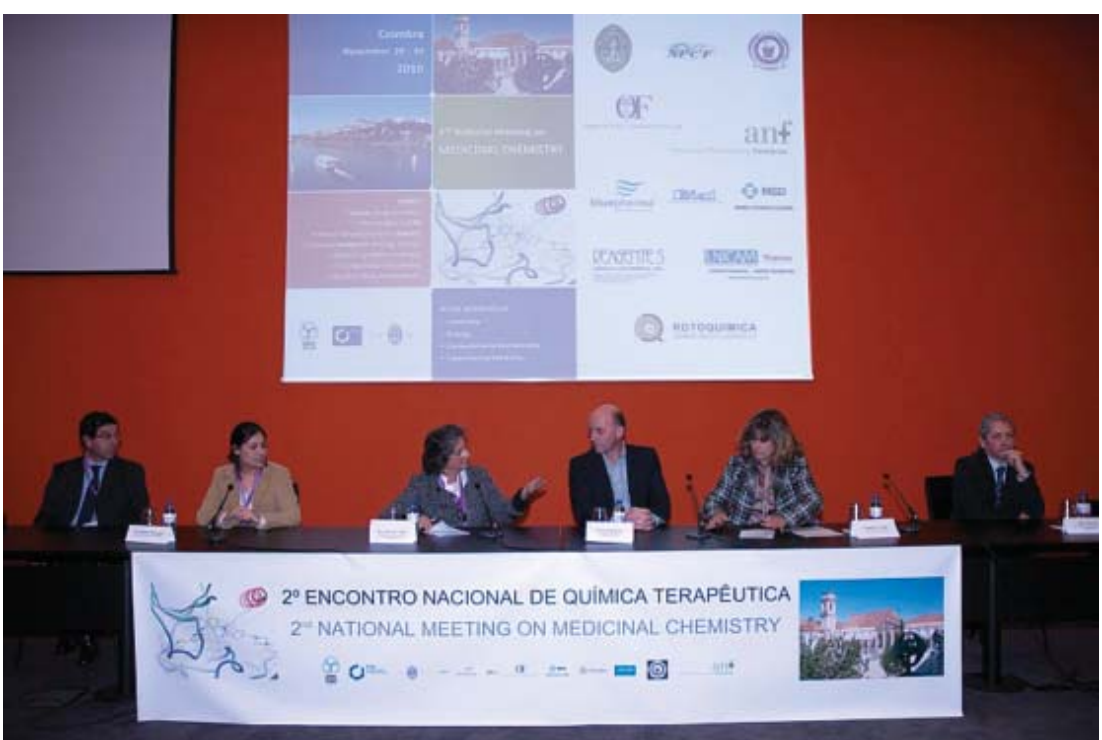

Sessão de trabalhos

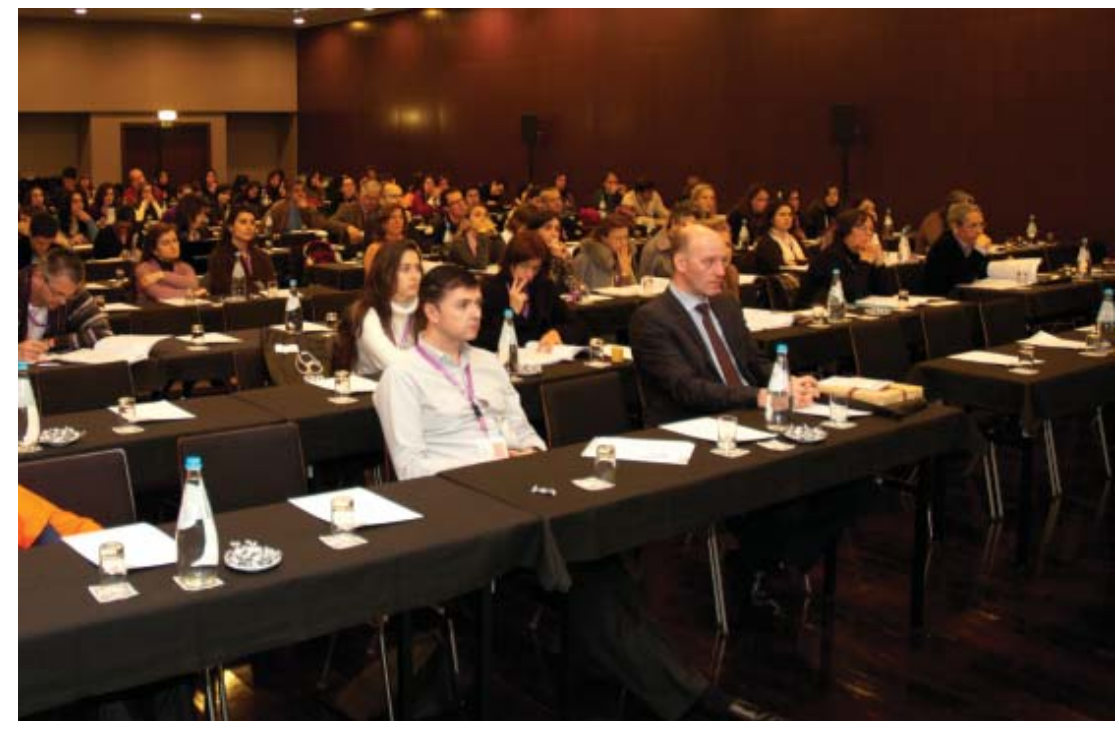

Assistência do $2^{\circ}$ Encontro Nacional de Química Terapêutica 2010 da malária, os avanços em sondas químicas para estudos biológicos, os métodos de síntese actuais, os novos processos na descoberta de fármacos e a modelização molecular e design racional de fármacos.

O Encontro contou com a participação activa de 16 convidados, que proferiram 5 conferências plenárias e 11 conferências convidadas.

A conferência plenária de abertura, a "Lecture Bluepharma", proferida por Stephen Neidle da School of Phar- macy, University of London e intitulada "21st Century cancer drug discovery by selective gene targeting", perspectivou como o actual conhecimento dos genes envolvidos no cancro e da sua multiplicidade de mutações têm permitido melhorias significativas no tratamento de alguns carcinomas, com especial focagem nos quadruplexes como alvos terapêuticos para pequenas moléculas, com aplicação em situações malignas do pâncreas e do tracto gastro-intestinal.

Koen Augustyns, da University of Antwerp, centrou-se na experiência de dois laboratórios desta universidade, o Laboratório de Química Medicinal e o de Bioquímica Médica que, através da implementação de um programa conjunto de investigação básica, elucidaram a função da enzima dipeptidil peptidase IV e desenvolveram novos inibidores, sendo esta plenária intitulada "Inhibitors of dipeptidyl peptidases: from drug discovery to the clinic".

Giorgio Colombo, do Istituto di Chimica del Riconoscimento Molecolare, CNR, Milano, proferiu uma conferência plenária, intitulada "Structure-functiondynamics relationships in proteins: Implications for drug discovery", em que apresentou resultados recentes de estratégias de biologia computacional para a descoberta de novos inibidores 
de interacções proteína-proteína com propriedades "drug-like" e de estudos de dinâmica funcional e de mecanismos de propagação alostérica de sinal em proteínas.

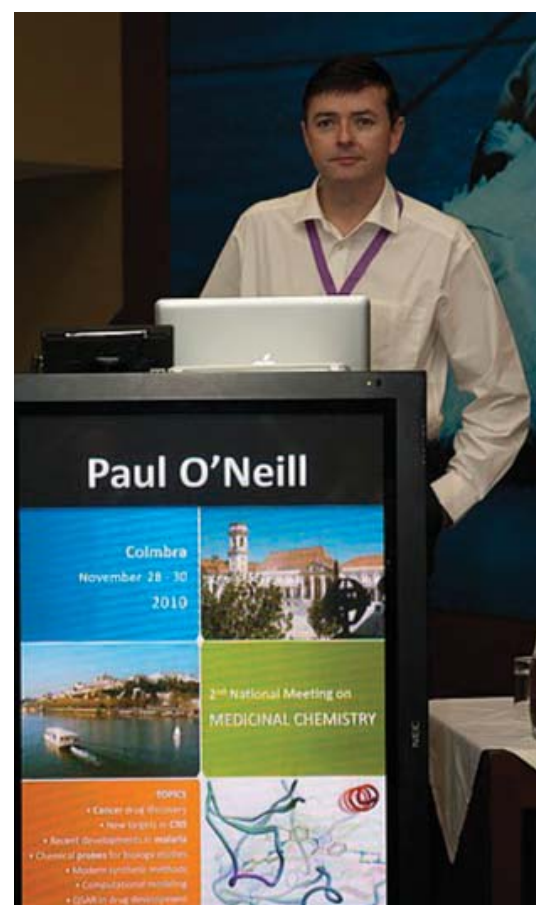

Sessão plenária proferida pelo Professor Paul O'Neill (University of Liverpool)
Paul O'Neill, da University of Liverpool, apresentou o tema: "Synthetic endoperoxide antimalarial; identification of a drug development candidate and back-up molecules with superior properties to the artemisins and OZ277". Esta plenária focou os estudos para a elucidação de mecanismos de acção deste tipo de antimaláricos, o uso de dois componentes activos numa só entidade química e um estudo muito completo de optimização de antimaláricos endoperóxidos.

Heinz Beck, da University of Bonn Medical Center, proferiu a "Lecture BIAL", intitulada "New molecular targets for drug discovery in CNS: Linking the target to the disease(s)", em que abordou a epilepsia, os conceitos que explicam a resistência aos fármacos e os mecanismos de acção emergentes, a nível celular e molecular, que poderão levar a novas estratégias para o desenvolvimento de novas terapêuticas.

Foram ainda apresentadas 27 comunicações orais seleccionadas e 200 comunicações em painel, que aborda- ram tópicos interdisciplinares em Química Terapêutica e que contribuíram para o sucesso desta reunião científica, demonstrando o interesse dos investigadores mais jovens por esta área da Química, os quais responderam cabalmente ao nosso encorajamento para participarem e comunicarem neste forum.

Nesta conferência teve ainda lugar a reunião do Grupo de Química Terapêutica, onde mereceu especial destaque a notícia da candidatura do Grupo/SPQ, recentemente aprovada pela European Federation for Medicinal Chemistry, EFMC, para a realização do XXIIIrd International Symposium on Medicinal Chemistry, o EFMC-ISMC 2014, em Lisboa.

Nesta reunião foi eleita a nova Comissão Directiva, que passou a ser composta pelos Profs. Artur Silva, Fernanda Proença, Madalena Pinto e Rui Moreira.

M. Luísa Sá e Melo (samelo@ci.uc.pt) Presidente da Comissão Organizadora

\section{$4^{\circ}$ Encontro Nacional de Espectrometria de Massa (MS2010)}

A espectrometria de massa é uma das áreas de investigação científica mais importantes na actualidade e o suporte analítico e instrumental em diversos domínios científicos, destacando-se a química, as ciências da vida, saúde, ambiente, proteómica e nanotecnologias. Entre 1906 e 2005 foram atribuídos cinco prémios Nobel pelo desenvolvimento da espectrometria de massa, sendo de realçar em 2002 John Fenn e Koichi Tanaka, galardoados com o prémio Nobel da Química pelo desenvolvimento de métodos de desadsorção/ionizaçao suave para a análise por espectrometria de massa de macromoléculas biológicas, que abriu caminho para a universalidade da espectrometria de massa.

A espectrometria de massa tem uma forte tradição em Portugal e grande prestigio internacional, tendo sido recentemente reforçada e consolidada através da criação da Rede Nacional de Espectrometria de Massa (rnem.fc.ul.pt).

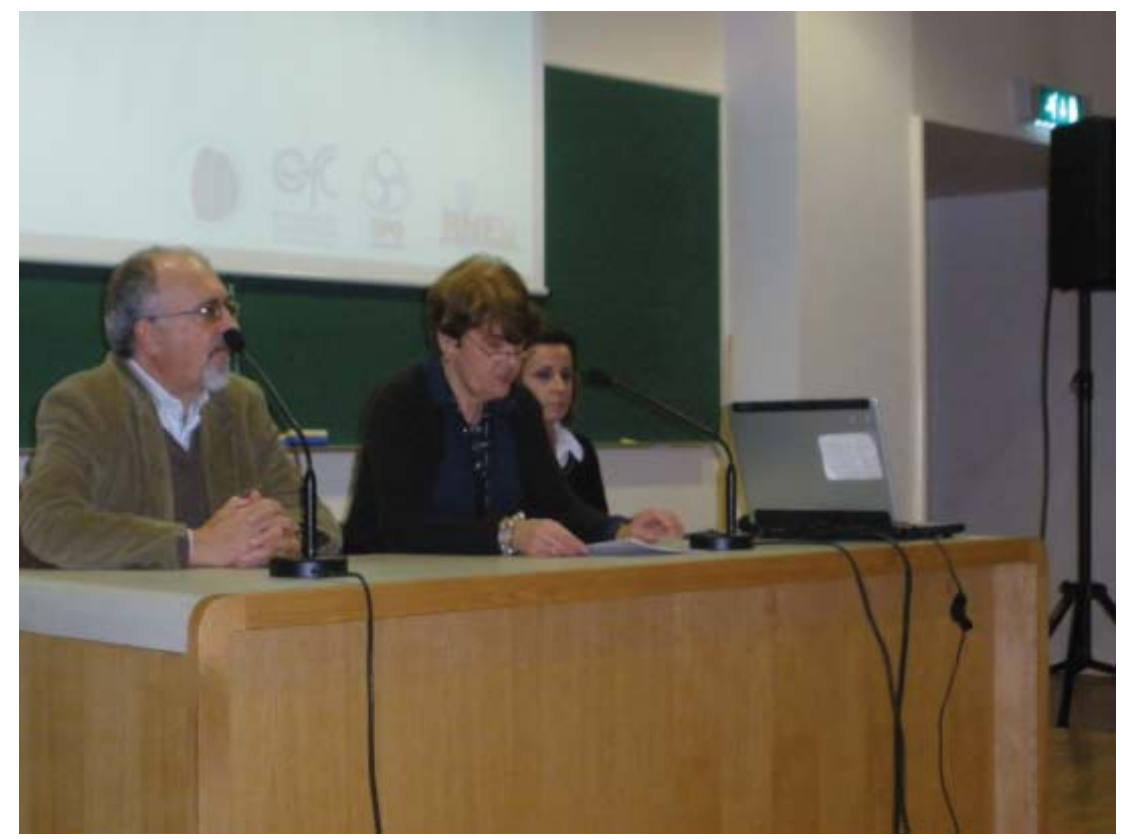

Figura 1 - Cerimónia de abertura do $4^{\circ}$ Encontro Nacional de Espectrometria de Massa, co-organizado pela Faculdade de Ciências da Universidade de Lisboa, Sociedade Portuguesa de Química e Rede Nacional de Espectrometria de Massa. A abertura foi realizada pela

Professora Helena Florêncio, Coordenadora da Rede Nacional de Espectrometria de Massa (ao centro) e contou com a presença do Presidente do Departamento de Química e Bioquímica e Coordenador do Centro de Ciências Moleculares e Materiais da FCUL, Professor Carlos Nieto de Castro e da Professora Ana Ponces Freire, Coordenadora do Centro de Química e Bioquímica da FCUL. Estes dois Centros de Investigaçao da FCUL albergam cerca de duas centenas de investigadores e têm a classificação de Very Good e Excellent, respectivamente 